in psychiatric patients. A few of them may be mentioned: the Buss-Durkee Hostility Inventory with its sub-scales including 'physical aggression' (Buss \& Durkee, 1957) or the Brown-Goodwin assessment for lifetime history of aggression (Brown et al, 1979). Assessment and classification of such complex phenomena as aggression should not be based on only one scale, especially in genetic studies with their substantial clinical and possibly forensic/legal implications. Nevertheless, we hope that this research may provide more insight into the biological mechanisms underlying aggression.

Brown, G. L., Goodwin, F. K., Ballenger, J. C., et al (1979) Aggression in humans: correlates with cerebrospinal fluid amine metabolites. Psychiatry Research, I, |3|-139.

Buss, A. H. \& Durkee, A. (1957) An inventory for assessing different kinds of hostility. Journal of Consulting Psychology, 2I, 343-349.

Jones, G., Zammit, S., Norton, N., et al (200I) Aggressive behaviour in patients with schizophrenia is associated with catechol-O-methyltransferase genotype. British Journal of Psychiatry, 179, 35I-355.

Monahan, J., Steadman, H. J., Appelbaum, P. S., et al (2000) Developing a clinically useful actuarial tool for assessing violence risk. British Journal of Psychiatry, I76, 312-319.

Sanders, J., Milne, S., Browne, P., et al (2000) Assessment of aggression in psychiatry admissions: semistructured interview and case note survey. BMJ, 320,1112

Schanda, H. \& Taylor, P. (200I) In-patient violence: frequency, risk factors, preventive strategies (in German). Fortschritte Neurologie Psychiatrie, 69, 443-452.

Soyka, M. \& Ufer, S. (2002) Aggression in schizophrenia: prevalence, psychopathological and sociodemographic correlates (in German). Fortschritte Neurologie Psychiatrie, in press.

Steadman, H. J., Mulvey, E. P., Monahan, J., et al (1998) Violence by people discharged from acute psychiatric inpatient facilities and by others in the same neighborhoods. Archives of General Psychiatry, 55, I-9.

_ , Silver, E., Monahan, J., et al (2000) A

classification tree approach to the development of actuarial violent risk assessment tools. Law and Human Behavior, 24, 83-100.

Swanson, J.W., Swartz, M. S., Borum, R., et al (2000) Involuntary out-patient commitment and reduction of violent behaviour in persons with severe mental illness. British Journal of Psychiatry, 176, 324-331.

Yudofski, S. C., Silver, J. M., Jackson, W., et al (1986) The Overt Aggression Scale for the objective rating of verbal and physical aggression. American Journal of Psychiatry, 143, 35-39.

Wallace, C., Mullen, P., Burgess, P., et al (1998) Serious criminal offending and mental disorder. Care linkage study. British Journal of Psychiatry, I72, 477-484.

M. Soyka Psychiatric Hospital, University of Munich, Nußbaumstr. 7, 80336 München, Germany; e-mail: Michael.Soyka@psy.med.uni-muenchen.de

\section{Post-traumatic stress disorder and management of stillbirth}

Lovett (2001), commenting on our article 'Incidence, correlates and predictors of post-traumatic stress disorder in the pregnancy after stillbirth' (Turton et al, 2001) took issue with our reporting a possible association between post-traumatic stress disorder and holding the dead infant which did not reach statistical significance.

We should like to make two points. First, we were at pains to make it clear that numbers were small and not significant statistically. Second, although your correspondent could not know this at the time of writing, we have subsequently published a paper reporting a significant relationship between seeing the dead infant and disorganisation of mother-infant attachment in the next-born child at the age of 12 months (Hughes et al, 2001). This was an unexpected finding for us.

Our main concern is that a profound change in clinical practice (seeing and holding the dead infant) was introduced with great enthusiasm in maternity units in the UK and elsewhere on the basis of limited and non-systematic clinical observation. Our published findings to date do not offer any evidence in support of this practice. We concur with Dr Lovett that this is an area which demands further investigation and rigorous evaluation.

Hughes, P., Turton, P., Hopper, E., et al (200I) Disorganised attachment behaviour among infants born subsequent to stillbirth. Journal of Child Psychology and Psychiatry, 42, 791-801.

Lovett, K. F. (200I) PTSD and stillbirth (letter). British Journal of Psychiatry, 179, 367.

Turton, P., Hughes, P., Evans, C. D. H., et al (200I) Incidence, correlates and predictors of post-traumatic stress disorder in the pregnancy after stillbirth. British Journal of Psychiatry, I78, 556-560.

P. Turton, P. Hughes Parent Child Research Group, Department of Psychiatry, Jenner Wing, St George's Hospital Medical School, London SWI7 ORE, UK

\section{Psychiatric morbidity and elderly offenders}

While I agree entirely with Fazel et al (2001) that there is an unmet need for psychiatric care for elderly offenders, I wonder whether this need is even greater than is implied by their paper. It is important not to forget those elderly people who do not actually end up in prison but have committed crimes. Yorston (1999) notes that the elderly are less likely than younger offenders to have custodial sentences or fines imposed and are more likely to receive probation orders. Lynch (1988) postulated that the public's sympathy for the perceived frailty of the elderly is likely to lead to this group being treated more leniently. Bergman \& Amir (1973) have also noted a tendency for families to hide deviance, which may lead to offending behaviour in this group being underreported.

One revelation to me which emerges from Fazel et al's paper was the relatively high number of offenders imprisoned for drug offences (29/203). Older studies (e.g. Taylor \& Parrott, 1988) suggested that drug-related crime was of a much lower incidence: indeed, in their study of elderly custodial remand prisoners none aged 55 and over had been charged with a drugrelated offence, although they noted that misuse of alcohol appeared to rise steadily with age. I wonder whether Fazel et al are showing us that the victims of the drugs culture, traditionally thought to have been established in the UK in the 1960s, are now starting to feature among the elderly?

Bergman, S. \& Amir, M. (1973) Crime and delinquency among aged in Israel. Israel Annals of Psychiatry and Related Disciplines, II, 33-48.

Fazel, S., Hope, T., O’Donnell, l., et al (200I) Hidden psychiatric morbidity in elderly prisoners. British Journal of Psychiatry, 179, 535-539.

Lynch, S. (1988) Criminality in the elderly and psychiatric disorder. A review of the literature. Medicine, Science and the Law, 28, 65-78.

Taylor, P. J. \& Parrott, J. M. (1988) Elderly offenders. A study of age-related factors among custodially remanded prisoners. British Journal of Psychiatry, 152 , 340-346.

Yorston, G. (1999) Aged and dangerous. Old age forensic psychiatry. British Journal of Psychiatry, 174, 193-195.

A.Thompsell Maudsley Hospital, Denmark Hill, London SE5 8AZ, UK

Elderly mentally disordered offenders are underresearched and poorly understood, but Fazel et al (2001a) demonstrated high levels of 'hidden' psychiatric morbidity in a sample of male prisoners over 60 years of age.

The cases of the former Chilean dictator Augusto Pinochet and of Ernest Saunders, involved in the Guinness financial affair, illustrated the inherent difficulties of the older person in the forensic setting. 
This was demonstrated when Saunders became the first case to make a full recovery from a diagnosis of Alzheimer's dementia.

In Fazel et al's two related papers $(2001 a, b)$, significant levels of both psychiatric and physical morbidity are clearly evident that will surely have future service implications as the elderly prisoner population continues its inevitable rise. Prison services for elderly inmates have been slow to develop despite the Reed report (Department of Health \& Home Office, 1992) that acknowledged the complex nature of elderly prisoners and demanded a 'holistic' approach in their management.

Yorston (1999) contemplates the future of old age forensic psychiatry as a subspeciality akin to those of learning disabilities and child and adolescent psychiatry. As the number of elderly mentally disordered offenders presenting currently is small, but increasing, he suggests that a regional tertiary referral service for the most difficult or serious cases, with close links between the relevant forensic and old age services, might be preferable at this time.

An integrated approach between old age and forensic services using their different areas of expertise will make assessment and management of elderly offenders more comprehensive, as opposed to management by one team alone. This is in keeping with standards 2 (person-centred care) and 7 (mental health) of the National Service Framework for Older People (Department of Health, 2001), which emphasise the importance of an integrated approach to assessment and care-planning through liaison with specialist services for older people. Standard 2 also suggests that the National Health Service and local councils should ensure a flexible and integrated approach to service provision, regardless of professional or organisational boundaries.

To date, elderly offender research has almost exclusively been retrospective but the studies by Fazel and colleagues suggest that a substantial prospective study of elderly offenders would not only be feasible but also desirable to improve our poor knowledge of this important group.

Department of Health (200I) National Service Framework for Older People. London: Stationery Office.

\& Home Office (1992) Review of Health and Social Services for Mentally Disordered Offenders and Others Requiring Similar Services. Final Summary Report (the Reed Report). Cm 2088. London: HMSO.

Fazel, S., Hope, T., O'Donnell, I., et al (200la) Hidden psychiatric morbidity in elderly prisoners. British Journal of Psychiatry, 179, 535-539.

_, _, _, et al (200lb) Health of elderly male prisoners: worse than the general population, worse than younger prisoners. Age and Ageing, 30, 403-407.

Yorston, G. (1999) Aged and dangerous. Old age forensic psychiatry. British Journal of Psychiatry, $\mathbf{1 7 4}$ 193-195.

M. Curtice Cossham Hospital, Lodge Road, Kingswood, Bristol BSI5 ILE, UK

\section{The evolutionary psychology debate}

I am very much honoured that a prominent scientific writer like Rose (2001) treats me with the same method as he and his circle have treated $\mathrm{E}$. O. Wilson in their recent collection of essays (Rose \& Rose, 2000). Being a mere practising psychiatrist, it puzzles me why it has become acceptable for the anti-sociobiology/evolutionary psychology movement to misquote their opposition, in either a patronising or an openly hostile way, attributing hidden agendas to those who dare to think about human behaviour and psychological functioning in an evolutionary context. Clearly, they feel that the end justifies the means, and that their version of the truth has to be defended at any cost.

Segerstråle (2000), in a detailed analysis of the sociobiology debate, compared the two camps of scientists to gardeners: one side representing the planters, and the other the weeders. It seems to me that both tasks are important in the development of the perfect garden of science. Rose appears to be an overzealous weeder, who is afraid that the dangerous weed of evolutionary psychology will destroy his garden and tries to kill it at every opportunity. The effort is unlikely to succeed. However, I need to point out that in my previous letters concerning the evolutionary psychology debate (Ayton, 2000, 2001) there was nothing to imply 'some sort of conspiracy in psychiatry to ignore biology' (Rose, 2001). About $30-40 \%$ of all psychiatric references on the Medline database are biological studies, so there is no lack of biological studies and theories. However, what is lacking is a coherent theoretical framework; and evolutionary theory is largely ignored by psychiatric training or academia. It is untenable to state that only proximal causation is relevant to mental states or human behaviour. This was recognised by Darwin and beautifully demonstrated by Bowlby. Despite initial strong criticism, Bowlby's contribution to the understanding of the mother-infant relationship has become fundamental, and has wiped out earlier explanations.

If 'nothing in biology makes sense except in the light of evolution' (Rose, 2001), then surely, human beings and their behaviour cannot be excluded on scientific grounds.

Ayton, A. (2000) Implications of evolutionary theory for psychiatry (letter). British Journal of Psychiatry, 177

- (200I) A defence of evolutionary psychology (letter). British Journal of Psychiatry, 179, 267-268.

Rose, H. \& Rose, S. (eds) (2000) Alas Poor Darwin Arguments Against Evolutionary Psychology. London: onathan Cape.

Rose, S. (200I) Revisiting evolutionary psychology and psychiatry (letter). British Journal of Psychiatry, I79, 558.

Segerstråle, U. (2000) Defenders of the Truth. The Sociobiology Debate. Oxford: Oxford University Press.

A. Ayton West End Child \& Family Service 2062-68 Hessle Road, Hessle HUI3 9NW, North Humberside, UK 